\title{
PARENT-DAUGHTER RELATIONSHIPS AND DISORDERED EATINGAMONG EMERGING ADULT WOMEN FROM THE CZECH REPUBLIC
}

\author{
Carlos A. ALMENARA, Tomo UMEMURA, Petr MACEK \\ Institute for Research on Children, Youth and Family (IVMDR) \\ Department of Psychology, Masaryk University \\ Joštova 10, Brno 602 00, Czech Republic \\ E-mail: carlos.almenara@mail.muni.cz
}

\begin{abstract}
The associations between parent-daughter relationship characteristics and disordered eating behaviors among emerging adult women from the Czech Republic were examined. Participants $(N=798$ women, $M=22.25$ years old, $S D=1.42)$ reported on disordered eating behaviors (dieting and unhealthy weight-control behaviors; UWCB), their relationship characteristics with each parent (trust, communication, alienation and psychological control) and covariates (weight, height, frequency of communication with parents, living status and parental statuses). Overall, $41 \%$ of women were on a diet, and $33 \%$ engaged in at least one UWCB. Logistic regression analyses revealed that none of the parent-daughter relationship characteristics had any association with dieting. However, a low quality of mother-daughter relationship (low trust, high alienation and psychological control) had a significant association with UWCB. None of the fatherdaughter relationship characteristics had a significant association with UWCB. The results suggest that preventive interventions with the family should emphasize the quality of the motherdaughter relationship.

Key words: attachment, disordered eating, emerging adulthood, parent-child relations, weight control
\end{abstract}

Many young women are engaged in weight-loss behaviors (Wardle, Haase, \& Steptoe, 2006), some of which are unhealthy (e.g., vomiting) and are likely to place them at risk of developing major health problems. Previous findings indicate that parentdaughter relationships have an important influence on the daughters' eating- and weight-related attitudes and behaviors dur-

\section{Acknowledgments}

This research was supported by the Czech Science Foundation (GAP407/12/0854). The first author (CA) acknowledges the support of the Czech Science Foundation (THINLINE-GA1505696S) and the Faculty of Social Studies at Masaryk University (Czech Republic). ing childhood and adolescence (e.g., Quiles Marcos, Quiles Sebastián, Pamies Aubalat, Botella Ausina, \& Treasure, 2013). However, the extent to which these influences operate after adolescence is less clear. Hence, the present study examines the association between current parent-daughter relationship characteristics and disordered eating behaviors among emerging adult women (18 to 29 years old).

\section{Disordered Eating Behaviors}

In order to lose weight some women engage in disordered eating behaviors, including unhealthy weight control behaviors 
(UWCB), such as skipping meals, or more extreme weight control behaviors (EWCB), such as self-induced vomiting (Larson, Neumark-Sztainer, \& Story, 2009). These disordered eating behaviors are associated with less healthy dietary patterns (Larson et al., 2009). Hence, it is important to understand the factors associated with the development of these disordered eating behaviors.

\section{Studies on Parent-Daughter Relation- ships and Disordered Eating Behaviors}

These studies can be divided into clinical and non-clinical ones. Traditionally, the first group has focused on the role of families in the etiology, psychopathology, treatment and maintenance of eating disorders. Most of these studies adhere to either family functioning theories or attachment theory (Holtom-Viesel \& Allan, 2014; see Tasca \& Balfour, 2014). However, many of these studies have been conducted with women who have already developed an eating disorder (including chronically ill patients) and the illness itself may affect family functioning (Holtom-Viesel \& Allan, 2014). Therefore, their findings can hardly be generalized. Furthermore, many of these studies have focused only on mother-daughter interactions (Ward, Ramsay, \& Treasure, 2000) and those including father data have tended to omit different family scenarios (e.g., fathers not living at home) (Gale, Cluett, \& LaverBradbury, 2013).

The second group of studies relies on the general non-clinical population, examining the associations between parent-daughter relationships and disordered eating. This approach is important for the prevention of eating and weight-related problems, because it might help identify risk/protective factors for the development of such problems. However, since the age of onset of eating disorders is typically early to late adolescence (Keel, Eddy, Thomas, \& Schwartz, 2010), these studies usually focus on this period or earlier periods of life. Again, it is difficult to generalize these findings to later periods, such as adulthood, and more research is needed to include periods of transition into adulthood (Keel et al., 2010).

\section{Parent-Daughter Relationships During Emerging Adulthood}

Emerging adulthood is an important contemporary developmental and transitional period, and typically occurs between the ages of 18 and 29 years (Arnett, 2015). Nowadays, young adults from many countries usually have a prolonged period of education, engage in uncommitted cohabitation and/or romantic relationships, and delay their marriage and childbirth (Arnett, 2015). During this period, emerging adults are in the process of achieving independence and autonomy from their parents (Arnett, 2015). Nevertheless, at the same time, parents can remain important figures for their daughter, and can continue to influence their daughter's eating attitudes and behaviors (Quiles Marcos et al., 2013). For instance, communication, a key factor in parent-daughter relationships, can distinctively influence eating attitudes and behaviors during emerging adulthood (Loth, MacLehose, Bucchianeri, Crow, \& Neumark-Sztainer, 2014) compared to adolescence (e.g., Al Sabbah et al., 2009). Furthermore, during emerging adulthood, parents may exert less control over their daughter, and are usually less likely to be involved in their daughter's decision-making processes than before (Arnett, 2015). 
However, the control parents exert, particularly psychological control, i.e., parental attempts of control that disrupt the psychological and emotional development of their daughter (Barber, 1996), may still have an effect during young adulthood (Soenens et al., 2008). For instance, psychological control has been associated with disordered eating behaviors during adolescence and young adulthood (Berge et al., 2014; Soenens et al., 2008). Therefore, it is important to examine whether certain characteristics of a parent-daughter relationship are significantly associated with disordered eating behaviors. In addition, it should be noted that the role of these parent-daughter relationship characteristics, such as psychological control and communication, are country specific (Al Sabbah et al., 2009; Quiles Marcos et al., 2013; Soenens \& Vansteenkiste, 2010). For instance, cultural variations in the expression of negative emotions may account for the cross-cultural differences found in the association between parent-child communication and body dissatisfaction (Al Sabbah et al., 2009). Therefore, parentdaughter relationship characteristics should be explored in different cultural contexts.

\section{The Present Study}

The present study will examine the association between current parent-daughter relationship characteristics and disordered eating behaviors. First, giving the widespread adoption of weight control behaviors among women (Wardle et al., 2006), we hypothesize that the prevalence of dieting and UWCB in our sample of Czech women will be similar to previous reports in Western countries. Second, based on previous findings outlined above, we hypothesize in general terms a sig- nificant association between a low quality in the parent-daughter relationship and disordered eating behaviors.

Several variables will be considered as potential covariates. The first potential covariate will be body mass index (BMI) because the probability of weight loss attempts is consistently higher among overweight women than non-overweight women (Wardle et al., 2006). The second one will be the frequency of communication with parents, because this study specifically examines the quality - not the quantity - of parent-daughter relationships. The third one will be living status (i.e., living vs. not living with parents) because previous studies suggest that emerging adults who live away from their parents are more likely to have a better relationship with them than those who live together or nearby (e.g., Aquilino, 2006). Biological parental status (biological parents vs. non-biological parents) and marital parental status (parents living together vs. parents not living together) will also be included as covariates, because some family structures might influence parent-daughter relationships. Finally, demographic characteristics (education, age) will be included as well.

\section{Method}

\section{Procedure and Participants}

The data and ethical approval for this study were drawn from the "Paths to adulthood" project, an ongoing longitudinal study that focuses on the psychosocial development of emerging adults in the Czech Republic (Macek et al., 2016; Umemura, Lacinová, \& Macek, 2015). The major aims of this project are to explore the process of transition from adolescence to adulthood and 
to describe the individual psychological characteristics specific to this period. In the year of 2012, we randomly selected universities, secondary schools, companies, and employment offices in the Czech Republic and then asked whether anyone wanted to participate in this project ( $26 \%$ of the participants were recruited in this way). We also non-randomly recruited $16 \%$ of participants in person (e.g., instructors announced our project in their classes). Finally, we also made announcements on our Psychology Department website and Facebook event page, newspapers, and local TV broadcasting ( $58 \%$ of the participants were recruited in this way).

Thus far, we completed five data collection periods (December 2012, March 2013, July 2013, December 2013, and March 2014). All the data for this study were collected during the fifth wave, except for the questions on education, which were from the first wave, and parents' marital statuses, which were from the third wave. Overall, 1,674 individuals provided informed consent in the first wave, and 1,091 participants participated in the fifth wave. As the final sample for this study, we selected only the subsample of 798 females aged 18 to 29 years $(M=22.25$, $S D=1.42$ ).

In this final sample, $32 \%$ completed graduate school; $60 \%$ finished college; $5 \%$ higher vocational school; $2 \%$ secondary school; and $1 \%$ specialized secondary school. As presented in Table 1, 23\% of the participants currently live with their parent(s), 93\% have both biological parents, and $38 \%$ of participants' parents are divorced or live separately. As compensation for participation, all respondents received brief reports from our study findings, and randomly selected respondents were given a t-shirt. All questionnaires were translated into Czech and were completed online via our university survey software.

We conducted missing data analyses. Females who remained in the fifth wave were more likely to have a higher level of education, $t(1237)=-2.09, p=.037$, and to have both biological parents, $\chi^{2}(1, \mathrm{~N}=974)=53.11$, $p<.001$, compared to females who participated only in the first wave. To minimize bias related to missing data, we controlled for these variables as covariates in our analyses.

\section{Measures}

Dieting to lose weight. The question on dieting was adopted from the Project EAT survey (see Loth et al., 2014). Participants were asked, "How often have you gone on a diet during the last year?" The following explanation was included to further clarify the idea of dieting: "By 'diet', we mean changing the way you eat so you can lose weight." The response options were: never, 1 to 4 times, 5 to 10 times, more than 10 times, and I am always dieting. Following the criteria of previous studies (Loth et al., 2014), respondents who reported having dieted at least once were classified as dieters (i.e., $1=$ dieters; $0=$ less frequent or non-dieters). For descriptive purposes, those who went on a diet five or more times during the last year were classified as chronic dieters.

Unhealthy weight control behaviors $(U W C B)$. The question assessing UWCB was also adopted from the Project EAT. Participants were asked, "Have you done any of the following things in order to lose weight or keep from gaining weight during the past year? "Nine UWCB were evaluated (e.g., fasting, eating very little food, etc.). 
Consistent with previous studies (Loth et al., 2014), we used a dichotomous categorization $(1=$ women who conducted at least one $U W C B ; 0=$ no $U W C B)$. For descriptive purposes, respondents who reported at least one of the following extreme weight control behaviors (EWCB): taking diet pills, vomiting, using laxatives, were categorized ( 1 = women who conducted at least one EWCB; $0=$ no $E W C B$ ).

Quality of parent-daughter relationships. We used the Inventory of Parent and Peer Attachment (IPPA) (Armsden \& Greenberg, 1987). Participants rated three dimensions of their relationship quality with each parent: trust (5 items; e.g., my mother respects my feelings), communication (4 items; e.g., I tell my father about my problems and troubles), and alienation (6 items; e.g., I get upset a lot more than my mother knows about). The original IPPA comprises 25 items, but based on previous studies using different Czech adolescent datasets (Širůček \& Lacinová, 2008) and a pilot study with 60 emerging adults, we selected 15 items measured on a 4-point scale ranging from 1 (absolutely true) to 4 (never true). In this sample, Cronbach's alphas for adolescents' trust, communication, and alienation subscales were $.87, .82$, and .74 for their mother and $.85, .83$, and .70 for their father, respectively.

Psychological control. We used the Psychological Control Scale -Youth Self-Report (PCS-YSR) (Barber, 1996). It has 8 items (e.g., my mother is a person who is always trying to change how I feel or think about things) measured on a 4-point Likert scale $(1=a b s o$ lutely true; $4=$ never true). Given that Cronbach's alphas for the items of both mothers and fathers' scales were high (.82 and .79 , respectively), we averaged all the items into composite scores.
Body mass index (BMI). Participants selfreported their weight and height. BMI was then calculated by dividing the weight in kilograms by the square of the height in meters.

The frequency of parent-daughter communication. We asked participants to respond, "How often do you have a personal contact with your parents? " separately for each parent on a 5-point Likert scale $(1=$ less than once per month; 5 = every day or almost every day).

Living status. Participants were asked, "With whom do you live?" Five options were given, I live with my parent(s); I live with my partner; I live with my friends or roommates; I live alone; and other. Then, a dichotomous variable was created $(1=$ living with parents; $0=$ not living with parents).

Parental statuses. Participants selected the best description of their parental status: biological mother and father; biological mother and her partner; biological father and his partner; and someone else. Given that $93 \%$ of participants had both biological parents, we developed a dichotomous variable $(1=$ biological parents $; 0=$ others $)$. In addition, to obtain the information about their parents' marital status (divorced or living separately vs. living together), participants responded to the following item: both of my parents live together $(1=n o ; 0=y e s)$.

\section{Results}

\section{Descriptive Analyses}

Table 1 presents means (with standard deviations) or percentages of variables and covariates. During the last year, $41 \%$ of emerging adult women went on a diet at least once, and $33 \%$ reported at least one UWCB. The frequency of each UWCB in decreasing 
Table 1 Descriptive statistics for study variables and covariates

\begin{tabular}{|c|c|c|c|}
\hline Variables & $M(S D)$ or $\%$ & $\mathrm{n}$ & Min. - Max. \\
\hline Unhealthy weight control behavior & $33 \%$ & 766 & $0-1$ \\
\hline Dieting & $41 \%$ & 773 & $0-1$ \\
\hline Trust with mother & $3.37(.63)$ & 708 & $1-4$ \\
\hline Trust with father & $3.22(.67)$ & 686 & $1-4$ \\
\hline Communication with mother & $3.15(.68)$ & 708 & $1-4$ \\
\hline Communication with father & $2.54(.72)$ & 679 & $1-4$ \\
\hline Alienation with mother & $2.06(.62)$ & 708 & $1-4$ \\
\hline Alienation with father & $2.28(.63)$ & 681 & $1-4$ \\
\hline Psychological control by mother & $1.83(.58)$ & 685 & $1-4$ \\
\hline Psychological control by father & $1.68(.51)$ & 656 & $1-4$ \\
\hline \multicolumn{4}{|l|}{ Covariates } \\
\hline Body mass index & $22.25(3.55)$ & 759 & $14.69-43.94$ \\
\hline Frequency of communication with mother & $3.56(.88)$ & 775 & $1-5$ \\
\hline Frequency of communication with father & $2.90(.98)$ & 756 & $1-5$ \\
\hline Living with parent(s) & $23 \%$ & 798 & $0-1$ \\
\hline Parental status (biological) & $93 \%$ & 772 & $0-1$ \\
\hline Parental status (marital) & $38 \%$ & 798 & $0-1$ \\
\hline Education $^{\mathrm{a}}$ & $6.12(1.35)$ & 777 & $1-9$ \\
\hline Age $^{\mathrm{b}}$ & $22.25(1.42)$ & 798 & $18.83-28.17$ \\
\hline
\end{tabular}

Note. Min. $=$ Minimum. Max. $=$ Maximum. aOur measure of education ranges from elementary school (1) to doctoral program (9). bAge is coded as years

order included: skipping meals (18.2\%), eating very little food $(15.6 \%)$, using food substitutes (powder/special drink) (10.6\%), following a high protein/low carbohydrate diet (e.g., Atkins or other) (4.6\%), fasting (4\%), smoking more cigarettes (3.7\%), taking diet pills $(1.7 \%)$, self-induced vomiting $(0.9 \%)$, and taking laxatives $(0.1 \%)$. Furthermore, $8.5 \%$ of participants were classified as chronic dieters (went on a diet more than five times during the last year), and $2.5 \%$ of participants engaged in at least one EWCB during the last year.
Correlations among variables are presented in Table 2. Dieting did not correlate with any measures, except for a small correlation with psychological control by the father. By contrast, UWCB were significantly associated with the mother's and father's trust, alienation, and psychological control. The correlations of UWCB with communication with both parents were very low and significant only for communication with the mother. In addition, correlations of covariates with UWCB and dieting are presented in Table 3. BMI was associated with both 
Table 2 Correlation coefficients among study variables

\begin{tabular}{|c|c|c|c|c|c|c|c|c|c|}
\hline Variables & 1 & 2 & 3 & 4 & 5 & 6 & 7 & 8 & 9 \\
\hline 1 Unhealthy weight control behavior & & & & & & & & & \\
\hline 2 Dieting & $.39^{* * *}$ & & & & & & & & \\
\hline 3 Trust with mother & $-.15^{* * *}$ & -.02 & & & & & & & \\
\hline 4 Trust with father & $-.15^{* * *}$ & -.07 & $.38^{* * *}$ & & & & & & \\
\hline 5 Communication with mother & $-.09^{*}$ & .02 & $.73^{* * *}$ & $.28^{* * *}$ & & & & & \\
\hline 6 Communication with father & -.06 & .02 & $.29^{* * *}$ & $.72^{* * *}$ & $.42^{* * *}$ & & & & \\
\hline 7 Alienation with mother & $.17^{* * *}$ & .05 & $-.68^{* * *}$ & $-.36^{* * *}$ & $-.65^{* * *}$ & $-.35^{* * *}$ & & & \\
\hline 8 Alienation with father & $.16^{* * *}$ & .06 & $-.34^{* * *}$ & $-.70^{* * *}$ & $-.33^{* * *}$ & $-.62^{* * *}$ & $.65^{* * *}$ & & \\
\hline 9 Psychological control by mother & $.15^{* * *}$ & .07 & $-.68^{* * *}$ & $-.32^{* * *}$ & $-.47^{* * *}$ & $-.26^{* * *}$ & $.66^{* * *}$ & $.41^{* * *}$ & \\
\hline 10 Psychological control by father & $.14^{* * *}$ & $.08^{*}$ & $-.22^{* * *}$ & $-.55^{* * *}$ & $-.15^{* * *}$ & $-.31^{* * *}$ & $.32^{* * *}$ & $.57^{* * *}$ & $.46^{* * *}$ \\
\hline
\end{tabular}

Table 3 Correlation coefficients of covariates with unhealthy weight control behaviors (UWCB) and dieting

\begin{tabular}{lcc}
\hline Variables & UWCB & Dieting \\
\hline Body mass index (BMI) & $.11^{* *}$ & $.31^{* * *}$ \\
Frequency of communication with mother & -.00 & .03 \\
Frequency of communication with father & $-.08^{*}$ & .01 \\
Living with parent(s) & -.02 & .03 \\
Parental status (biological) & -.05 & -.02 \\
Parental status (marital) & .06 & -.06 \\
Education & $-.09^{* *}$ & -.03 \\
Age & -.06 & -.06 \\
\hline
\end{tabular}

$* \mathrm{p}<.05, * * \mathrm{p}<.01 . * * * \mathrm{p}<.001$

UWCB and dieting. Lower frequency of communication with the father and lower education level were related toUWCB(not dieting).

\section{Logistic Regression Analyses}

To further understand whether these associations remain significant or non-significant after controlling for covariates and whether mothers or fathers play important roles in emerging adults' dieting and UWCB, a series of logistic regression analyses were conducted. Firstly, we included dieting as the outcome variable and accounted for the following covariates: BMI, the frequency of communication with each parent, living status, parental statuses (biological and marital), education, and age. To minimize a problem of multicollinearity, a different set of independent variables was included in each analysis separately. These variables were 1) trust with mother and father, 2) communication with mother and father, 3 ) alienation with mother and father, and 4) mother's and 


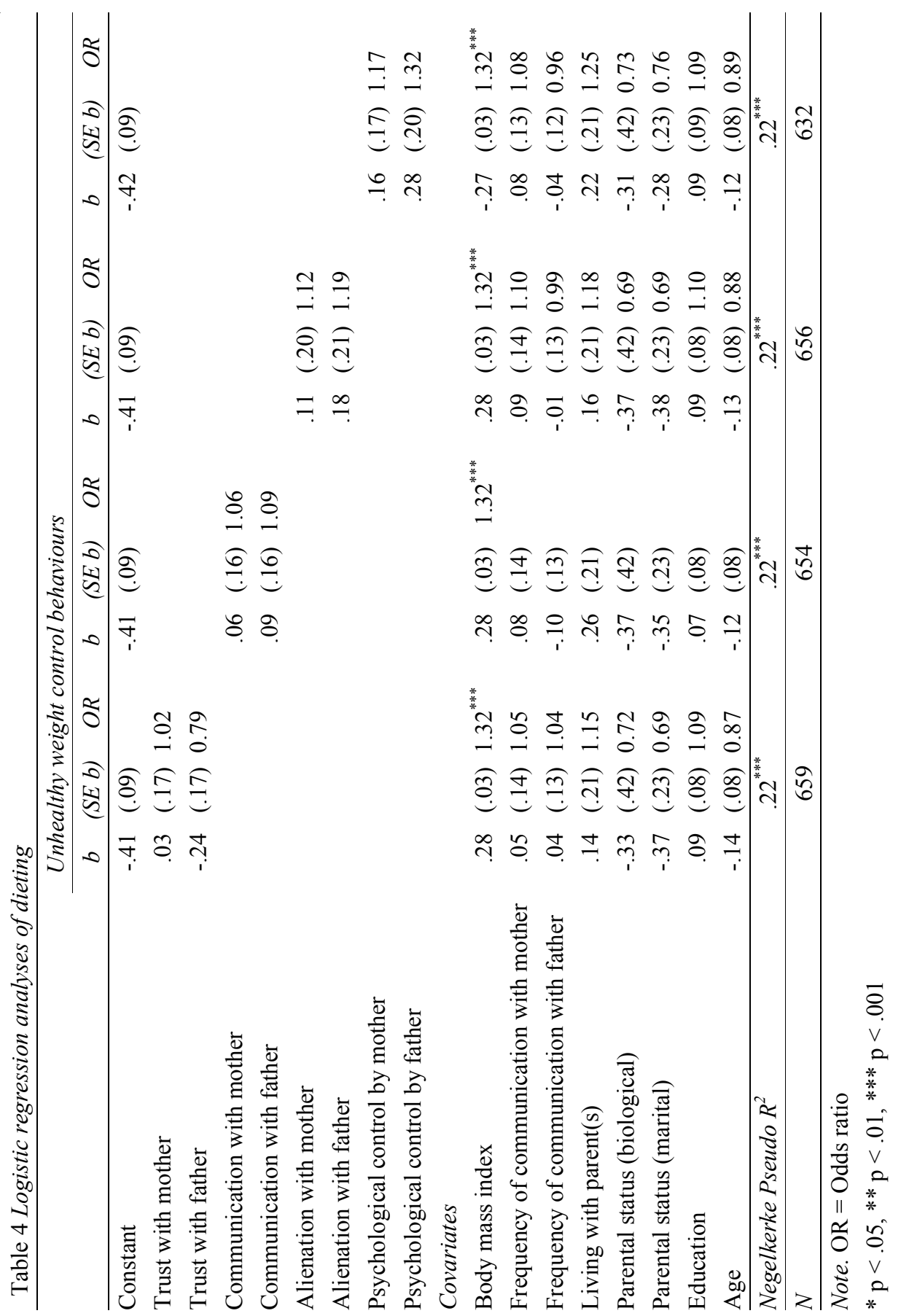




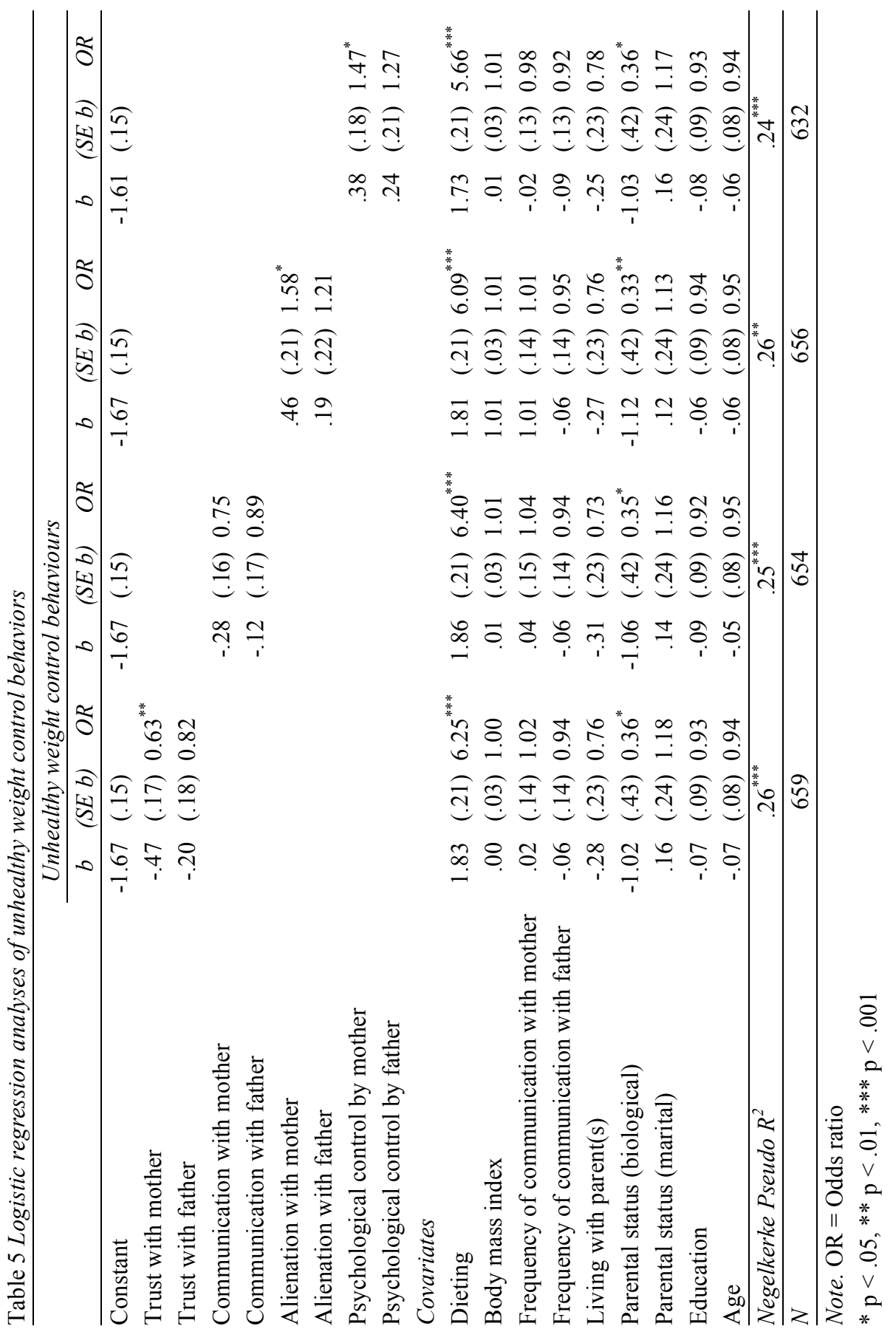


father's psychological control. The results revealed that none of emerging adult women's relationship characteristics with their parents had any association with dieting to lose weight (see Table 4).

Secondly, UWCB was included as the outcome variable, and dieting was added to the covariates. Concerning motherdaughter relationship characteristics, trust, alienation, and psychological control had a significant association with UWCB, whereas mother-daughter communication did not. By contrast, none of the fatherdaughter relationship characteristics had any significant association with UWCB (see Table 5). Thus, these results indicated that in father-daughter relationships, after adjusting for covariates, none of the characteristics examined had any association with UWCB, whereas low trust, high alienation, and high psychological control in motherdaughter relationships had a significant association with UWCB after adjusting for covariates.

\section{Discussion}

Like many women in other countries (Wardle et al., 2006), we found that Czech women also go on diets and engage in unhealthy weight control behaviors (UWCB). This may reflect the widespread adoption of Western values that glorify the feminine ideal of beauty (typically a slender body), the importance of physical appearance and the "fear of fatness" (see Jung \& Forbes, 2010). Indeed, recent Czech studies have found children and adolescents expressing negative attitudes toward overweight bodies (Almenara \& Ježek, 2015), a sharp and solid increase in the consumption of slimming products in spite of the negative impact of the global financial crisis (Euromonitor International, 2014), and a considerable increase in hospital admissions for eating disorders since communism ceased (Pavlova, Uher, Dragomirecka, \& Papezova, 2010).

Due to the prevalence of disordered eating behaviors and the key role of body dissatisfaction in their development, health programs should promote body acceptance (Bucchianeri \& Neumark-Sztainer, 2014). A venue for it is through guidance for parents which is considered an important factor in promoting body acceptance and healthy habits in the family (Bucchianeri \& NeumarkSztainer, 2014).

The results of our regression analyses show that the low quality of mother-daughter relationships is significantly associated with disordered eating behaviors. A compelling explanation could be the high level of involvement and intimacy between daughters and mothers. At this age, daughters usually seek advice mainly on personal matters from their mothers and spend more time with them compared to fathers (Nielsen, 2012). This pattern of closeness does not differ much across cultures, because the traditional role of the mother is usually that of the primary caretaker (Georgas et al., 2001). This applies to the Czech Republic as well, where family functioning has not changed substantially over the past 20 years (Šerek, Macek, Ježek, \& Lacinová, 2014). In this scenario of emotional closeness, a poor relationship between the mother and her daughter could set the stage for disordered eating. Indeed, the literature on family and eating disorders is rich in allusions to abnormal family interactions, particularly between mothers and their daughters (Ward et al., 2000).

Nevertheless, our cross-sectional results, along with mixed past findings, cannot be 
conclusive. Typically, studies on family relationships and disordered eating are not consistent in methodology and are characterized by marked differences in conceptualization and measurement, which could explain the inconsistency of the findings. For instance, cross-sectional studies have found that disordered eating among young adult women has been associated with problems in communication with the father (Miller-Day \& Fisher, 2008), although this has not been apparent in longitudinal studies from adolescence to young adulthood (Loth et al., 2014). Similarly, psychological control by either parent seems to increase the likelihood of dieting and UWCB among adolescent girls (Berge et al., 2014). But studies on young adult women suggest it would be only psychological control by the father, whereas psychological control by the mother would have an indirect influence through mediating mechanisms such as maladaptive perfectionism (Soenens et al., 2008) or moderating the relationship between body dissatisfaction and disordered eating (Sira \& White, 2010). Thus, an important avenue for future research is to further explore these parental influences as well as daughters' mediating/ moderating mechanisms such as body dissatisfaction, internalization of appearance ideals, appearance anxiety and personality traits (Rodgers \& Chabrol, 2009; Soenens et al., 2008; Tetley, Moghaddam, Dawson, \& Rennoldson, 2014). Furthermore, recent review papers share a common idea that there are no particular patterns in family functioning associated with eating disorders; rather, family functioning is diverse (Holtom-Viesel \& Allan, 2014; Konstantellou, Campbell, \& Eisler, 2012; Le Grange, Lock, Loeb, \& Nicholls, 2010). Invariably, these researches also agree that family has an important role to play in the development of disordered eating behaviors (Hart, Cornell, Damiano, \& Paxton, 2015; Konstantellou et al., 2012; Le Grange et al., 2010; Steinberg \& Phares, 2001), and that attention should be given to potential areas in the family that may work as protective factors and are key for prevention and intervention (Konstantellou et al., 2012; Steinberg \& Phares, 2001).

In this context, an important implication suggested by our results is the conceivable early intervention to prevent eating- and weight-related problems by emphasizing the quality of the mother-daughter relationship. Indeed, an intervention directed only at mothers resulted in mothers exerting less pressure toward their daughters to be thin and their daughters showing less of a wish to be thinner (Corning, Gondoli, Bucchianeri, \& Salafia, 2010). This approach could be particularly useful when the daughter and/or father are reluctant to participate in prevention or intervention programs. Moreover, mental health literacy and nutritional knowledge should be increased among families (Hart et al., 2015) to recognize the importance of certain eating behaviors and to identify unhealthy eating patterns, particularly UWCB, which often persist through emerging adulthood (Loth et al., 2014).

\section{Strengths and Limitations}

Our study contributes by including data related to each parent, family factors as covariates, a non-clinical sample and multiple dimensions of parent-daughter relationship characteristics. Specifically, our study overcame previous limitations by including data on each parent as well as on family factors (i.e., frequency of communication with each parent, living status and 
parental statuses). Furthermore, many previous studies have employed clinical samples, whereas we had a non-clinical sample and used the Inventory of Parent and Peer Attachment (IPPA), which is an instrument designed for the general population, rather than for those with disturbed family relations (Vignoli \& Mallet, 2004). Moreover, most of the studies using the IPPA have analyzed only the total score of the scale (obtained by summing trust and communication subscales' scores and subtracting from this sum the alienation subscale score), which reduces the parentoffspring relationship to only one dimension (Vignoli \& Mallet, 2004). To address this limitation we analyzed the data separately without merging it. However, it should be noted that we collected the data on only four characteristics of parent-daughter relationships (trust, communication, alienation and psychological control). Thus, these data cannot fully cover all possible aspects of these relationships. Therefore, a more comprehensive assessment would be necessary. For instance, real-time data capture and mixed-method approaches (combining quantitative and qualitative methods) could cover more specific aspects of family interactions, such as the content of communication (see Baiocchi-Wagner, 2015; Hart et al., 2015).

Nevertheless, our results should be interpreted with caution because of their self-reported nature, our cross-sectional study design and our non-representative sample. Specifically, we collected the data from daughters only (not from parents). Future studies could consider also including parents' perceptions of the relationship with their daughters, although the sole reliance on parent's reports should be treated with cau- tion as well (Hart et al., 2015). Importantly, the cross-sectional nature of our study precludes drawing causal conclusions. A lowquality relationship between mother and daughter could lead to the development of disordered eating, but the poor relationship could also be in response to the disordered eating behaviors (Konstantellou et al., 2012; Le Grange et al., 2014; Soh, Touyz, \& Surgenor, 2006; Steinberg \& Phares, 2001). Therefore, future research should consider that family interactions are not unidirectional but rather characterized as mutual reciprocity (see Baiocchi-Wagner, 2015). Moreover, as we have discussed above, future studies should explore mediating and moderating factors in the association between parentdaughter relationships and disordered eating behaviors. Finally, our sample does not represent the entire population of the Czech Republic, and the results we obtained could be different in other samples as well as in other cultural contexts.

\section{Conclusions}

In conclusion, the prevalence of disordered eating behaviors in Czech emergingadult women is noteworthy. In our study, the quality of parents-daughter relationships was not associated with dieting to lose weight. However, the low quality of mother-daughter relationships (not father-daughter relationships), comprising low trust, high alienation and high psychological control, was significantly associated with unhealthy weight-control behaviors. Intervention programs and early prevention initiatives could help by improving the quality of motherdaughter relationships. Future research should explore how the association between parent-daughter relationships and disor- 
dered eating behaviors can be mediated and/ or moderated by other variables.

Received October 6, 2015

\section{References}

Al Sabbah, H., Vereecken, C. A., Elgar, F. J., Nansel, T., Aasvee, K., Abdeen, Z., ... \& Maes, L. (2009). Body weight dissatisfaction and communication with parents among adolescents in 24 countries: International cross-sectional survey. $B M C P u b$ lic Health, 9, 52. doi:10.1186/1471-2458-9-52

Almenara, C. A., \& Ježek, S. (2015). The source and impact of appearance teasing: An examination by sex and weight status among early adolescents from the Czech Republic. Journal of School Health, 85(3), 163-170. doi:10.1111/josh.12236

Aquilino, W. S. (2006). Family relationships and support systems in emerging adulthood. In J. J. Arnett \& J. L. Tanner (Eds.), Emerging adults in America: Coming of age in the 21st century (pp. 193-217). Washington, DC: American Psychological Association. doi:10.1037/11381-000

Armsden, G. C., \& Greenberg, M. T. (1987). The Inventory of Parent and Peer Attachment: Individual differences and their relationship to psychological well-being in adolescence. Journal of Youth and Adolescence, 16(5), 427-454. doi: $10.1007 / \mathrm{BF} 02202939$

Arnett, J. J. (2015). Emerging adulthood: The winding road from the late teens through the twenties (2nd ed.). New York, NY: Oxford University Press.

Baiocchi-Wagner, E. A. (2015). Future directions in communication research: Individual health behaviors and the influence of family communication. Health Communication, 30(8), 810-819. doi:10.1080/10410236.2013.845492

Barber, B. K. (1996). Parental psychological control: Revisiting a neglected construct. Child Development, 67(6), 3296-3319. doi:10.1111/ j.1467-8624.1996.tb01915.x

Berge, J. M., Wall, M. M., Larson, N. I., Eisenberg, M. E., Loth, K. A., \& Neumark-Sztainer, D. R. (2014). The unique and additive associations of family functioning and parenting practices with disordered eating behaviors in diverse adolescents. Journal of Behavioral Medicine, 37(2), 205-217. doi: 10.1007/s10865-012-9478-1

Bucchianeri, M. M., \& Neumark-Sztainer, D. R. (2014). Body dissatisfaction: An overlooked pub- lic health concern. Journal of Public Mental Health, 13(2), 64-69. doi:10.1108/JPMH-112013-0071

Corning, A. F., Gondoli, D. M., Bucchianeri, M. M., \& Salafia, E. H. B. (2010). Preventing the development of body issues in adolescent girls through intervention with their mothers. Body Image, 7(4), 289-295. doi:10.1016/j.bodyim.2010. 08.001

Euromonitor International. (2014). Weight management in the Czech Republic. London: Euromonitor International Ltd.

Gale, C. J., Cluett, E. R., \& Laver-Bradbury, C. (2013). A review of the father-child relationship in the development and maintenance of adolescent anorexia and bulimia nervosa. Issues in Comprehensive Pediatric Nursing, 36(1-2), 48-69. doi:10.3109/01460862.2013.779764

Georgas, J., Mylonas, K., Bafiti, T., Poortinga, Y. H., Christakopoulou, S., Kagitcibasi, C., ... \& Kodiç, Y. (2001). Functional relationships in the nuclear and extended family: A 16-culture study. International Journal of Psychology, 36(5), 289300. doi:10.1080/00207590143000045

Hart, L. M., Cornell, C., Damiano, S. R., \& Paxton, S. J. (2015). Parents and prevention: A systematic review of interventions involving parents that aim to prevent body dissatisfaction or eating disorders. The International Journal of Eating Disorders, 48(2), 157-169. doi:10.1002/ eat. 22284

Holtom-Viesel, A., \& Allan, S. (2014). A systematic review of the literature on family functioning across all eating disorder diagnoses in comparison to control families. Clinical Psychology Review, 34(1), 29-43. doi:10.1016/j.cpr.2013. 10.005

Jung, J., \& Forbes, G. B. (2010). Body dissatisfaction and disordered eating: The globalization of Western appearance ideals. In M. A. Paludi (Ed.), Feminism and women's rights worldwide (Vol. 1, pp. 161-186). Santa Barbara, CA: Praeger.

Keel, P. K., Eddy, K. T., Thomas, J. J., \& Schwartz, M. B. (2010). Vulnerability to eating disorders across the lifespan. In R. E. Ingram \& J. M. Price (Eds.), Vulnerability to psychopathology: Risk across the lifespan (2nd ed., pp. 489-494). New York, NY: The Guilford Press.

Konstantellou, A., Campbell, M., \& Eisler, I. (2012). The family context: Cause, effect or resource. In J. Alexander \& J. Treasure (Eds.), A collaborative approach to eating disorders (pp. 5-18). New York, NY: Routledge. 
Larson, N. I., Neumark-Sztainer, D. R., \& Story, M. T. (2009). Weight control behaviors and dietary intake among adolescents and young adults: Longitudinal findings from Project EAT. Journal of the American Dietetic Association, 109(11), 1869-1877. doi:10.1016/j.jada.2009. 08.016

Le Grange, D., Lock, J. D., Loeb, K., \& Nicholls, D. (2010). Academy for Eating Disorders position paper: The role of the family in eating disorders. The International Journal of Eating Disorders, 43(1), 1-5. doi:10.1002/eat.20751

Le Grange, D., O’Connor, M., Hughes, E. K., Macdonald, J., Little, K., \& Olsson, C. A. (2014). Developmental antecedents of abnormal eating attitudes and behaviors in adolescence. International Journal of Eating Disorders, 47(7), 813824. doi:10.1002/eat.22331

Loth, K. A., MacLehose, R., Bucchianeri, M. M., Crow, S. J., \& Neumark-Sztainer, D. R. (2014). Predictors of dieting and disordered eating behaviors from adolescence to young adulthood. The Journal of Adolescent Health, 55(5), $705-$ 712. doi: $10.1016 /$ j.jadohealth.2014.04.016

Macek, P., Ježek, S., Lacinová, L., Bouša, O., Kvitkovičová, L., Neužilová-Michalčáková, R. \& Širůček, J. (2016). Emerging adults in the Czech Republic: Views into and across different domains of life. In R. Žukauskiené (Ed.), Emerging adulthood in a European context (pp. 175-202). New York, NY: Psychology Press.

Miller-Day, M. A., \& Fisher, C. L. (2008). Parentemerging adult child communication and disordered eating patterns. In J. N. Fuchs (Ed.), Eating disorders in adult women (pp. 1-19). New York, NY: Nova Science Publishers.

Nielsen, L. (2012). Father-daughter relationships: Contemporary research and issues. New York, NY: Routledge.

Pavlova, B., Uher, R., Dragomirecka, E., \& Papezova, H. (2010). Trends in hospital admissions for eating disorders in a country undergoing a socio-cultural transition, the Czech Republic 1981-2005. Social Psychiatry and Psychiatric Epidemiology, 45(5), 541-550. doi:10.1007/ s00127-009-0092-7

Quiles Marcos, Y., Quiles Sebastián, M. J., Pamies Aubalat, L., Botella Ausina, J., \& Treasure, J. (2013). Peer and family influence in eating disorders: A meta-analysis. European Psychiatry, 28(4), 199-206. doi:10.1016/j.eurpsy.2012. 03.005

Rodgers, R. F., \& Chabrol, H. (2009). Parental attitudes, body image disturbance and disordered eat- ing amongst adolescents and young adults: A review. European Eating Disorders Review, 17(2), 137-151. doi:10.1002/erv.907

Šerek, J., Macek, P., Ježek, S., \& Lacinová, L. (2014). Twenty years after the Velvet Revolution: Shifts in Czech adolescents' perceptions of family, school, and society. Journal of Adolescent Research, 29(6), 738-764. doi:10.1177/ 0743558414538315

Sira, N., \& White, C. P. (2010). Individual and familial correlates of body satisfaction in male and female college students. Journal of American College Health, 58(6), 507-514. doi:10.1080/ 07448481003621742

Širůček, J., \& Lacinová, L. (2008). Relationships with parents from the perspective of attachment theory. In S. Ježek \& L. Lacinová (Eds.), Fifteen-year-olds in Brno: A slice of longitudinal self-reports (pp. 123-130). Brno: Masaryk University.

Soenens, B., \& Vansteenkiste, M. (2010). A theoretical upgrade of the concept of parental psychological control: Proposing new insights on the basis of self-determination theory. Developmental Review, 30(1), 74-99. doi:10.1016/ j.dr.2009.11.001

Soenens, B., Vansteenkiste, M., Vandereycken, W., Luyten, P., Sierens, E., \& Goossens, L. (2008). Perceived parental psychological control and eating-disordered symptoms: Maladaptive perfectionism as a possible intervening variable. The Journal of Nervous and Mental Disease, 196(2), 144-152. doi:10.1097/NMD. 0b013e318162aabf

Soh, N. L., Touyz, S. W., \& Surgenor, L. J. (2006). Eating and body image disturbances across cultures: A review. European Eating Disorders Review, 14(1), 54-65. doi:10.1002/erv.678

Steinberg, A. R., \& Phares, V. (2001). Family functioning, body image, and eating disturbances. In J. K. Thompson \& L. Smolak (Eds.), Body image, eating disorders, and obesity in youth: Assessment, prevention, and treatment (pp. 127147). Washington, DC: American Psychological Association.

Tasca, G. A., \& Balfour, L. (2014). Attachment and eating disorders: A review of current research. The International Journal of Eating Disorders, 47(7), 710-717. doi:10.1002/ eat. 22302

Tetley, A., Moghaddam, N. G., Dawson, D. L., \& Rennoldson, M. (2014). Parental bonding and eating disorders: A systematic review. Eating Be- 
haviors, 15(1), 49-59. doi:10.1016/j.eatbeh. 2013.10.008

Umemura, T., Lacinová, L., \& Macek, P. (2015).

Is emerging adults' attachment preference for the romantic partner transferred from their attachment preferences for their mother, father, and friends? Emerging Adulthood, 3(3), 179193. doi: $10.1177 / 2167696814561767$

Vignoli, E., \& Mallet, P. (2004). Validation of a brief measure of adolescents' parent attachment based on Armsden and Greenberg's three-dimension model. Revue Européenne de Psychologie
Appliquée, 54(4), 251-260. doi:10.1016/j.erap. 2004.04 .003

Ward, A., Ramsay, R., \& Treasure, J. (2000). Attachment research in eating disorders. British Journal of Medical Psychology, 73(1), 35-51. doi:10.1348/000711200160282

Wardle, J., Haase, A. M., \& Steptoe, A. (2006). Body image and weight control in young adults: International comparisons in university students from 22 countries. International Journal of Obesity (2005), 30(4), 644-651. doi:10.1038/sj. ijo.0803050 